\title{
Ganoderma lucidum polysaccharides eradicates the blocking effect of fibrinogen on NK cytotoxicity against melanoma cells
}

\author{
SHENG ZHENG, YANPING JIA, JUN ZHAO, QUN WEI and YUEHUALIU \\ Department of Applied Chemistry and Biological Engineering, Northeast Dianli University, Jilin 132012, P.R. China
}

Received August 25, 2011; Accepted November 28, 2011

DOI: $10.3892 / \mathrm{ol} .2011 .515$

\begin{abstract}
Natural killer (NK) cell cytotoxicity is an effective defense against metastatic tumor cells or viruses in the blood. However, NK cytotoxicity against tumor cells may be inhibited by a fibrinogen coat adhered to the surface of tumor cells. Ganoderma lucidum (G. lucidum) polysaccharides have been reported for their inhibitory ability on the adhesion of type I collagen, hyaluronan, fibronectin and laminin to integrins that were highly expressed on melanoma cells, and were therefore capable of enhancing NK cytotoxicity to tumor cells. In this study, we investigated the effect of G. lucidum polysaccharides on fibrinogen's adhesion to melanoma cells and NK cytotoxicity to tumor cells. Melanoma cells B16 and A375 were cultured and analyzed using flow cytometry. Human NK cells were isolated and analyzed using an NK cytotoxic assay. The results showed that polysaccharides extracted from G. lucidum inhibit the adhesion of fibrinogen to melanoma cells, and reverse the blocking effect of the fibrin coat on NK cytotoxicity against melanoma cells.
\end{abstract}

\section{Introduction}

It is well known that metastasis of tumor cells is the main cause of mortality in patients with cancer, and this is a hot topic for investigators. Metastasis is a multi-step and highly regulated cascade process, in which tumor cells separate from a primary foci, cross the wall of vessels, circulate through the whole organism within the blood, and eventually form new colonies at remote sites following adhesion to the endothelium (1). The majority of tumor cells are killed by the immune system during circulation in the vessels $(2,3)$, and natural killer cells (NK cells) are one of the main cellular immune factors. The anti-metastasis function of NK cells has been reported in various models of experimental and spontaneous metastasis $(4,5)$. In these reports, it is well accepted that

Correspondence to: Dr Sheng Zheng, Department of Applied Chemistry and Biological Engineering, Northeast Dianli University, 169 Changchun Road, Jilin 132012, P.R. China

E-mail: zhengs@mail.nedu.edu.cn

Key words: Ganoderma lucidum polysaccharides, NK cytotoxicity, fibrinogen, integrin direct contact between NK cells and tumor cells is crucial (6). Therefore, the mechanism by which the surviving tumor cells avoid lethal contact with NK cells is a key topic for anti-cancer research. Various studies have demonstrated that a number of blood coagulation factors facilitate the hematogenous metastasis of tumor cells $(7,8)$. These factors contribute to tumor angiogenesis, stroma formation, growth or metastasis (9-11). Of all the known effects of cancer progression, the protective effect of fibrinogen to tumor cells has been well probed. A mass of fibrinogen may adhere to tumor cells tightly, and coat the tumor cells to form a protective shield, which inhibits the effector-target interaction and subsequently blocks NK cytotoxicity against tumor cells $(12,13)$.

Ganoderma lucidum (G. lucidum) has been widely used as a traditional herb for disease treatment and health promotion, particularly by cancer patients. G. lucidum polysaccharides have been reported that may significantly promote the immune parameters of patients with advanced cancer (14). In their study, Sliva et al demonstrated that G. lucidum inhibits the migration of various cancer cells $(15,16)$. The antitumor activities of the polysaccharides appear to be due to different mechanisms, such as inhibition of adhesion of tumor cells to type I collagen, hyaluronan, fibronectin and laminin, promotion of the expression of cytokines, promotion of tumor cells to induce lymphocyte proliferation and suppression of tumor-induced angiogenesis (17-20). This study was designed to observe the effect of G. lucidum polysaccharides on the adhesion of fibrinogen to melanoma cells and NK cytotoxicity to tumor cells. We found that fibrinogen is capable of adhering to the melanoma cells B16 and A375, and that $\alpha_{5} \beta_{1}$ and $\alpha_{\mathrm{v}} \beta_{3}$ integrin are essential for adhesion. Coated fibrin may protect melanoma cells from NK cytotoxicity, and G. lucidum polysaccharides are capable of eliminating the adhesion of fibrinogen to tumor cells, and then eradicating the blocking effect of fibrinogen on NK cytotoxicity against melanoma cells and decreasing the lung metastasis of melanoma cells in mice.

\section{Materials and methods}

Reagents. Fibrinogen conjugated with Alexa Fluor 488 and IMDM culture medium was purchased from Invitrogen (OR, USA), and fibrinogen was purchased from Sigma-Aldrich (St. Louis, MO, USA). Blocking antibodies of mouse $\beta_{1}$ (Biolegend, CA, USA, HMb1-1) and mouse $\beta_{3}$ integrins (Santa Cruz Biotechnology, Santa Cruz, CA, USA, 2C9.G2), human 
$\alpha_{5} \beta_{1}$ (Chemicon, Millipore, Billerica, MA, USA, HA5) and human $\alpha_{v} \beta_{3}$ integrins (Santa Cruz Biotechnology, HM2034) were prepared according to the manufacturer's instructions. G. lucidum polysaccharides were purchased from Johnsun Mushroom (Hangzhou, China), and dissolved in phosphatebuffered saline (PBS).

Cells and animals. Melanoma cells B16 and A375 were obtained from the Shanghai Cell Bank (Chinese Academy of Science, Shanghai, China). Cells were cultured in IMDM medium and $10 \%$ fetal bovine serum (FBS) was added in a humidified cell incubator $\left(37^{\circ} \mathrm{C}, 5 \% \mathrm{CO}_{2}\right)$. These cells were harvested with trypsin and EDTA. Subsequently, PBS-washed cells were suspended in culture medium for further use. Six- to eight-week-old C57B1/6J healthy male mice (specific pathogen free) were obtained from the Jilin University Animal Center (Changchun, China). All of the protocols applied in the animal experiments were approved by the Animal Care and Use Committee of Northeast Dianli University (Jilin, China).

Flow cytometric assay. Melanoma cells were harvested and resuspended in IMDM. For the adhesion assay, Alexa Fluor 488 conjugated fibrinogen (green fluorescence) was used. Each aliquot $(0.1 \mathrm{ml})$ of tumor cells was mixed with fibrinogen $(1 \mathrm{mg} / \mathrm{ml})$ and incubated at $37^{\circ} \mathrm{C}$ for $30 \mathrm{~min}$. After washing twice, cells were suspended in $0.5 \mathrm{ml}$ of PBS for further analysis by a flow cytometer (FACScan, Beckman-Coulter, Miami, FL, USA).

Preparation of NK cells. Human NK cells were isolated from human peripheral blood mononuclear cells (PBMCs) with a negative magnetic bead NK cell isolation kit (Miltenyi Biotec, Bergisch Gladbach, Germany). In brief, B cells, T cells, stem cells, monocytes, dendritic cells, granulocytes and erythroid cells were labeled by a cocktail of magnetically biotin-conjugated antibodies. Highly pure NK cells were separated by depletion of magnetically labeled cells in the MicroBead. Mouse NK cells were separated from spleen cells with a similar kit (Miltenyi Biotec).

NK cytotoxic assay. An NK cytotoxic assay was performed in the presence or absence of fibrinogen. In brief, $\mathrm{Na}^{51} \mathrm{CrO}_{4}$ pre-labeled tumor cells in $0.05 \mathrm{ml}\left(1 \times 10^{4}\right)$ culture medium were pre-incubated with $0.05 \mathrm{ml}$ of various concentrations of fibrinogen in the presence $(0.1 \mathrm{mg} / \mathrm{ml})$ or absence of G. lucidum polysaccharides for $30 \mathrm{~min}$ at $37^{\circ} \mathrm{C}$. Subsequently, 100:1 of NK cells $(0.05 \mathrm{ml})$ were added. Following $4 \mathrm{~h}$ of co-incubation at $37^{\circ} \mathrm{C}$, cell culture plates were centrifuged at $1500 \mathrm{rpm}$ for $10 \mathrm{~min}$, and supernatants $(0.05 \mathrm{ml})$ were collected for the radioactivity measurement. The cytotoxicity was measured using the formula $\%=(\mathrm{A}-\mathrm{B}) /(\mathrm{C}-\mathrm{B}) \times 100$, where $\mathrm{A}$ is radioactivity in the test well, $\mathrm{B}$ is spontaneous radioactivity from the well target cells without effect cells, and C is the total target released radioactivity.

Statistical analysis. Data were presented as the mean \pm SD. The significance of differences between the means was calculated by the analysis of variance. When the difference of the means was shown to be significant, multiple comparisons by pairs were calculated by the T-test. Probability values of $\mathrm{P}<0.001$,

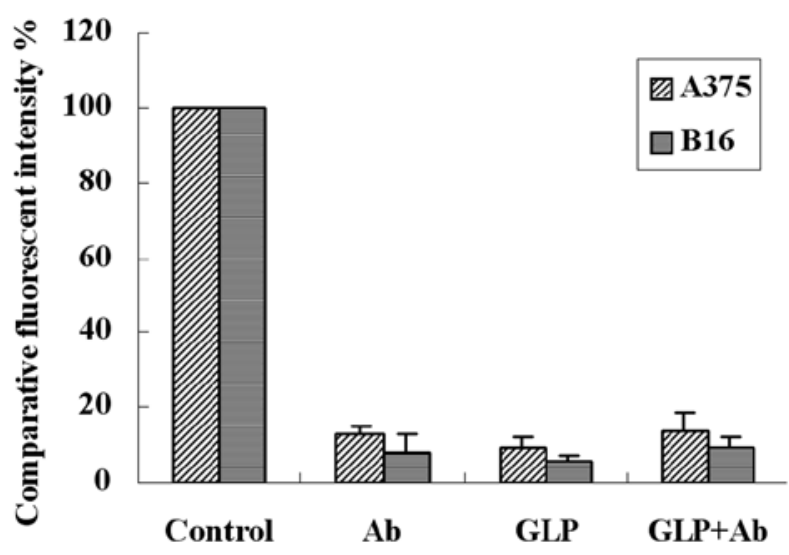

Figure 1. Fibrinogen binds to melanoma cells in an integrin-dependent manner. A total of $0.1 \mathrm{ml}$ of $2 \times 10^{5} \mathrm{~B} 16$ or A375 cells co-incubated with the same volume of $2 \mathrm{mg} / \mathrm{ml}$ fibrinogen conjugated with Alexa Fluor488. Function blocking antibodies of $\alpha_{v} \beta_{3}$ and $\alpha_{5} \beta_{1}$ integrins were added separately $\left(\alpha_{v} \beta_{3}\right.$ and $\alpha_{5} \beta_{1}$ ) or together (Ab). The average fluorescent intensity was compared with the assays to which PBS had been added (control).

$\mathrm{P}<0.01$ or $\mathrm{P}<0.05$ were considered to indicate a statistically significant difference.

\section{Results}

Fibrinogen binds to A375 and B16 cells in a $\alpha_{v} \beta_{3}$ and $\alpha_{5} \beta_{1}$ integrin-dependent manner. Fibrinogen is known to adhere to $\alpha_{v} \beta_{3}$ and $\alpha_{v} \beta_{1}$ integrins on the surface of tumor cells. To confirm the adhesion of fibrinogen to the tumor cells we used, fibrinogen conjugated with Alexa Fluor 488 was incubated with $\mathrm{B} 16$ or $\mathrm{A} 375$ cells at $37^{\circ} \mathrm{C}$ for 30 min with or without sufficient blocking antibodies. The results showed that fibrinogen strongly bound to the A375 ( 94\%) and B $16(\sim 98 \%)$ cell surface. Both $\alpha_{v} \beta_{3}$ and $\alpha_{5} \beta_{1}$ integrins bind to fibrinogen. In A375 and B16 cells, total eradication of the adhesion appeared when the functions of the two integrins were blocked (Fig. 1). Our results revealed that these two types of integrins mediated the adhesion of melanoma cells to fibrinogen.

Fibrinogen protects tumor cells from NK cytotoxicity. Fibrinogen may be coated on tumor cells and may protect these cells from NK cytotoxicity. Moreover, the adhesion of fibrinogen to tumor cells is essential. Melanoma cells strongly adhere to fibrinogen (Fig. 1). Therefore, we examined the ability of fibrinogen to protect melanoma cells from NK cytotoxicity. The results revealed that fibrinogen was capable of protecting tumor cells from NK cytotoxicity in a concentrationdependent manner (Fig. 2).

G. lucidum polysaccharides block the adhesion of fibrinogen to melanoma cells. To observe the effects of G. lucidum polysaccharides, we added them into the flow cytometric adhesion system. The results revealed that G. lucidum polysaccharides inhibited adhesion to the level of the blocking antibodies, and the combination of G. lucidum polysaccharides and antibodies (GLP+Ab) had no further blocking effect (Fig. 3). The results suggest that $G$. lucidum polysaccharides eradicate melanoma cell-fibrinogen adhesion by blocking $\alpha_{v} \beta_{3}$ and $\alpha_{5} \beta_{1}$ integrins. 


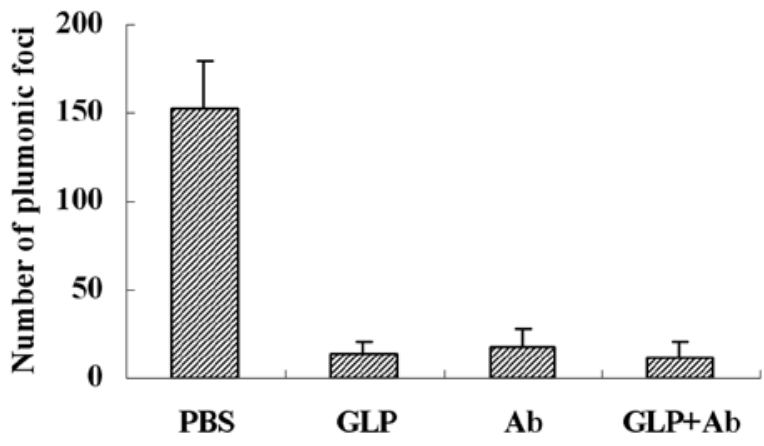

Figure 2. Fibrinogen blocks the NK cytotoxicity against melanoma cells. A total of $0.05 \mathrm{ml}$ of $1 \times 10^{4}{ }^{51} \mathrm{Cr}$-labeled B16 or A375 cells were co-cultured with various densities of fibrinogen for $30 \mathrm{~min}$. Cells were then co-incubated with $0.05 \mathrm{ml}$ of $1 \times 10^{6} \mathrm{NK}$ cells for $4 \mathrm{~h}$ to check the effect of fibrinogen on NK cytotoxicity.

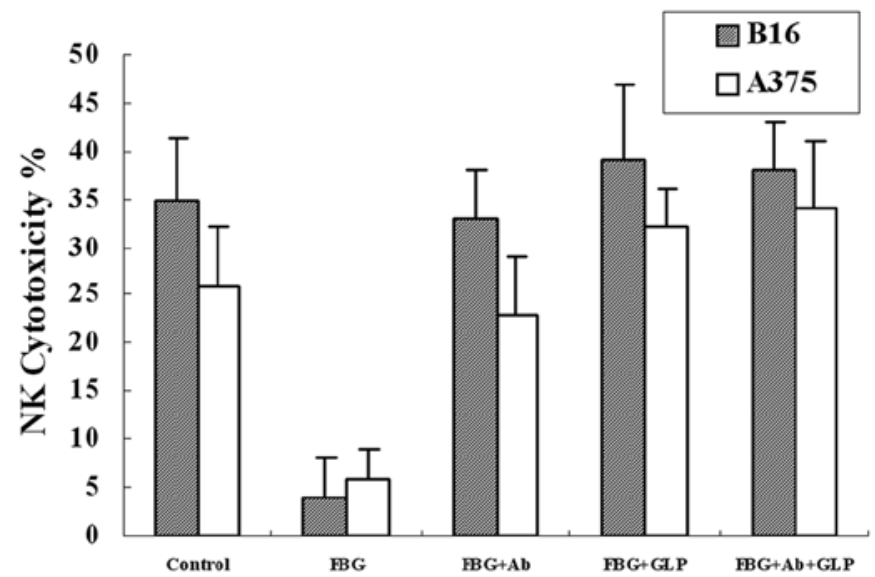

Figure 3. G. lucidum polysaccharides block the adhesion of fibrinogen to melanoma cells. G. lucidum polysaccharides (GLP) or antibodies (Ab, a combination of antibodies to $\alpha_{\mathrm{v}} \beta_{3}$ and $\alpha_{5} \beta_{1}$ integrins) of integrins were added into the flow cytometric system prior to the addition of fluorescent fibrinogen, separately or together $(\mathrm{GLP}+\mathrm{Ab})$.

G. lucidum polysaccharides eradicates the blocking effect of fibrinogen on NK cytotoxicity against melanoma cells. Fibrinogen coats are capable of blocking NK cytotoxicity against melanoma cells, and fibrinogen adhesion mediated by $\alpha_{v} \beta_{3}$ and $\alpha_{5} \beta_{1}$ integrins are eliminated by G. lucidum polysaccharides. Therefore, we examined the effect of G. lucidum polysaccharides on NK cytotoxicity affected by fibrinogen. The results showed that G. lucidum polysaccharides (FBG+GLP) reduced the blocking effect to almost the level of the control (Fig. 4). The results were also similar to the samples with antibodies added (FBG+Ab), and a combination of G. lucidum polysaccharides and antibodies $(\mathrm{FBG}+\mathrm{Ab}+\mathrm{GLP})$ revealed no further improvement. Our results suggested that G. lucidum polysaccharides are able to eliminate the blocking effect of fibrinogen on NK cytotoxicity to melanoma cells.

G. lucidum polysaccharides decrease the lung metastasis of melanoma cells in mice. NK cytotoxicity is an important immune defense for tumor metastasis, which may be blocked by fibrinogen, and G. lucidum polysaccharides may eliminate

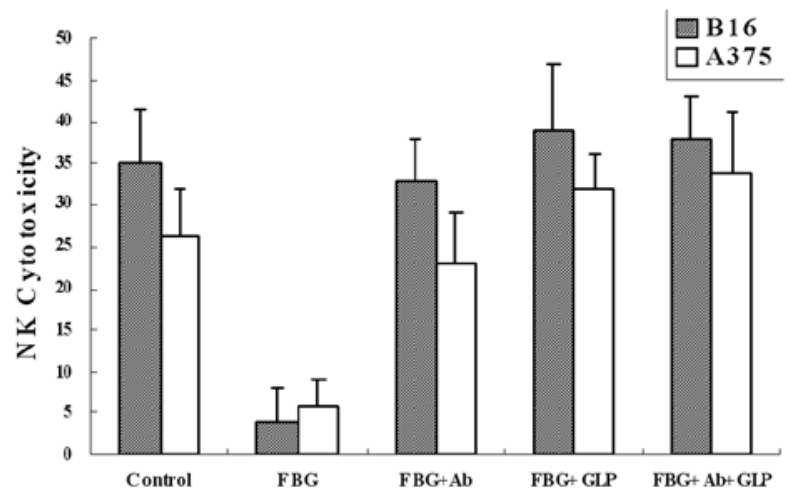

Figure 4. G. lucidum polysaccharides block the adhesion of fibrinogen to melanoma cells. G. lucidum polysaccharides (FBG+GLP) or antibodies $(\mathrm{FBG}+\mathrm{Ab})$ of integrins were added into the wells containing radio-labeled melanoma cells, separately or together (FBG+GLP+Ab). All of the wells, with the exception of the control (control) had fibrinogen added $30 \mathrm{~min}$ prior to injection of NK cells.

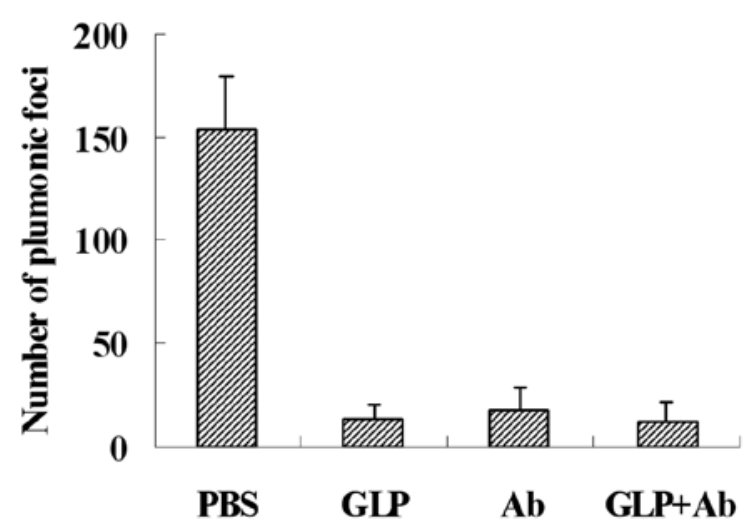

Figure 5. G. lucidum polysaccharides decrease the lung metastasis of B16 cells. B16 cells were injected into mice through the lateral tail vein following the injection of G. lucidum polysaccharides (GLP), antibodies (Ab) or both $(\mathrm{GLP}+\mathrm{Ab})$. Visible melanoma foci on the surface of murine lungs were counted 20 days following injection.

the blocking effect of fibrinogen on NK cytotoxicity against tumor cells. To detect the effect of G. lucidum polysaccharides on the metastasis of melanoma cells in a mouse model, we injected G. lucidum polysaccharides or function-blocking antibodies 5 min prior to injection of B16 tumor cells through the lateral tail vein. Our results, as shown in Fig. 5, shown that G. lucidum polysaccharides (GLP) and antibodies (Ab) decreased metastasis efficiently. The inhibitive rate of G. lucidum polysaccharides and antibodies was almost identical, and the combination of G. lucidum polysaccharides and antibodies $(\mathrm{GLP}+\mathrm{Ab})$ provided no further inhibition.

\section{Discussion}

It has been reported that G. lucidum polysaccharides is capable of eliminating the adhesion of tumor cells to various matrix proteins, including collagen, hyaluronan, fibronectin and laminin, and subsequently affecting the physiological phenomenon invoked by these proteins. Blood is rich in fibrinogen, and fibrinogen is capable of strongly blocking NK cytotoxicity. 
Although investigators have reported that G. lucidum polysaccharides improve the NK cell profile or cytokine secretion, the effects of G. lucidum polysaccharides on NK cytotoxicity blocked by fibrinogen have not previously been reported. In this study, we found that G. lucidum polysaccharides eliminate melanoma cell-fibrinogen adhesion mediated by $\alpha_{\mathrm{v}} \beta_{3}$ and $\alpha_{5} \beta_{1}$ integrins, and eradicate the blocking effect of fibrinogen on NK cytotoxicity against melanoma cells. We suggest that it is a new area of study of anti-cancer activity of G. lucidum polysaccharide.

\section{Acknowledgements}

This study was supported by grants from the National Natural Science Foundation of China (31101009), Doctoral Initiating Project of Northeast Dianli University of China (BSJXM-200905), and 'Twelfth Five' scientific and technological research projects from Jilin Provincial Department of Education (2011.74).

\section{References}

1. Liotta LA: Cancer cell invasion and metastasis. Sci Am 266: 54-59, 62-63, 1992.

2. Fidler I: Metastasis: quantitative analysis of distribution and fate of tumor emboli labeled with 125I-5 iodo-2-deoxyuridine. J Natl Cancer Inst 45: 773-779, 1970.

3. Mehdi AB, Tozawa K, Fisher AB, Shientag L, Lee A and Muschel RJ: Intravascular origin of metastasis from the proliferation of endothelium-attached tumor cells: a new model for metastasis. Nat Med 6: 100-102, 2000.

4. Gorelik E, Wiltrout RH, Okumura K, Habu S and Herberman RB: Role of NK cells in the control of metastatic spread and growth of tumor cells in mice. Int J Cancer 30: 107-112, 1982.

5. Hanna N: The role of natural killer cells in the control of tumor growth and metastasis. Biochim Biophys Acta 780: 213-226, 1985

6. Arnon TI, Achdout H, Lieberman N, Gazit R, Gonen-Gross T, Katz G, Bar-Ilan A, Bloushtain N, Lev M, Joseph A, Kedar E, Porgador A and Mandelboim O: The mechanisms controlling the recognition of tumor- and virus-infected cells by NKp46. Blood 103: 664-672, 2004.

7. Rickles FR and Falanga A: Molecular basis for the relationship between thrombosis and cancer. Thromb Res 102: V215-V224, 2001.
8. Terraube V, Pendu R, Baruch D, Gebbink MF, Meyer D, Lenting PJ and Denis CV: Increased metastatic potential of tumor cells in von Willebrand factor-deficient mice. J Thromb Haemost 4: 519-526, 2006.

9. Dvorak HF, Nagy JA, Berse B, Brown LF, Yeo KT, Yeo TK, Dvorak AM, van de Water L, Sioussat TM and Senger DR: Vascular permeability factor, fibrin, and the pathogenesis of tumor stroma formation. Ann N Y Acad Sci 667: 101-111, 1992.

10. Nierodzik ML and Karpatkin S: Thrombin induces tumor growth, metastasis, and angiogenesis: evidence for a thrombin-regulated dormant tumor phenotype. Cancer Cell 10: 355-362, 2006.

11. Langer F, Amirkhosravi A, Ingersoll SB, Walker JM, Spath B, Eifrig B, Bokemeyer C and Francis JL: Experimental metastasis and primary tumor growth in mice with hemophilia A. J Thromb Haemost 4: 1056-1062, 2006.

12. Gunji Y, Lewis J and Gorelik E: Fibrin formation inhibits the in vitro cytotoxic activity of human natural and lymphokine-activated killer cells. Blood Coagul Fibrinolysis 1: 663-672, 1990.

13. Atagi S, Sone S, Fukuta K and Ogura T: Inhibition by fibrin coagulation of lung cancer cell destruction by human interleukin-2-activated killer cells. Jpn J Cancer Res 83: 1088-1094, 1992.

14. Gao Y, Zhou S, Jiang W, Huang M and Dai X: Effects of ganopoly (a Ganoderma lucidum polysaccharide extract) on the immune functions in advanced-stage cancer patients. Immunol Invest 32: 201-215, 2003.

15. Sliva D, Labarrere C, Slivova V, Sedlak M, Lloyd FP Jr, Ho NW, et al: Ganoderma lucidum suppresses motility of highly invasive breast and prostate cancer cells. Biochem Biophys Res Commun 298: 603-612, 2002.

16. Sliva D: Ganoderma lucidum (Reishi) in cancer treatment. Integr Cancer Ther 2: 358-364, 2003.

17. Zhang $Q$ and Lin Z: Study on antitumour activity and mechanism of Ganoderma polysaccharides B. Zhongguo Zhong Xi Yi Jie He Za Zhi 19: 544-547, 1999

18. Sun LX, Lin ZB, Li XJ, Li M, Lu J, Duan XS, Ge ZH, Song YX, Xing EH and Li WD: Promoting effects of Ganoderma lucidum polysaccharides on B16F10 cells to activate lymphocytes. Basic Clin Pharmacol Toxicol 108: 149-154, 2011.

19. Wu QP, Xie YZ, Li SZ, La Pierre DP, Deng ZQ, Chen Q, Li C, Zhang Z, Guo J, Wong CKA, Daniel Y, Yee A and Burton BY: Tumour cell adhesion and integrin expression affected by Ganoderma lucidum. Enzyme Microb Technol 40: 32-41, 2006.

20. Kimura Y, Taniguchi M and Baba K: Antitumour and antimetastatic effects on liver of triterpenoid fractions of Ganoderma lucidum: mechanism of action and isolation of an active substance. Anticancer Res 22: 3309-3318, 2002. 